\title{
REPRESENTASI SASTRA PERJALANAN DALAM KUMPULAN CERPEN SURAT DARI PRAHA DAN ANTOLOGI PUISI KEPADA KAMU YANG DITUNGGU SALJU KARYA YUSRI FAJAR
}

\author{
Imam Shofi'i ${ }^{1}$, Tengsoe Tjahjono ${ }^{2}$ \\ Pascasarjana Universitas Negeri Surabaya, Surabaya, Indonesia \\ Surel: imam.shofii4@gmail.com
}

\begin{abstract}
Abstrak
Dalam beberapa tahun terakhir banyak buku telah diterbitkan yang memuat kisah perjalanan, baik perjalanan yang dilakukan di Indonesia maupun di luar negeri. Beberapa diterbitkan dalam bentuk cerita pendek, memoar, buku panduan perjalanan, bahkan puisi atau novel. Makalah ini diangkat sebagai bentuk respon positif terhadap fenomena tersebut. Cerita pendek dan puisi surat dari Praha dan untuk Anda yang menunggu karya salju Yusri Fajar menjadi salah satu kisah perjalanan yang menceritakan tentang perjalanan penulis. Dengan menggunakan perspektif yang berubah yaitu untuk menganalisis data dan kasus, penulis menggunakan teori konsep perjalanan menulis yang diusulkan oleh Carl Thompson dalam sebuah buku berjudul Travel Writing (2011). Penelitian ini menggambarkan perjalanan seseorang yang terkandung dalam kumpulan cerita pendek dan antologi puisi berjudul surat dari Praha dan untuk Anda yang menunggu salju oleh Yusri Fajar. Diri/orang asing mengalami dislokasi geografis, yang berakibat pada diri mereka sendiri dalam masyarakat dan budaya asing, yaitu Eropa. Studi ini meneliti cerita pendek dan puisi Yusri Fajar dalam kerangka literatur perjalanan seperti yang dijelaskan oleh Carl Thompson. Thompson menjelaskan bahwa ada tiga cara untuk melihat pola sastra perjalanan, yaitu dengan melihat penggambaran dunia, pengungkapan diri, dan representasi lainnya. Hasil penelitiannya adalah bahwa latar belakang diri/orang asing sebagai orang yang terasing bepergian dengan paksa ternyata mempengaruhi pola perjalanan sastra, yaitu dalam penggambaran dunia, pengungkapan diri dan representasi lainnya. Dari pola perjalanan sastra dapat dilihat bahwa diri memiliki dunia yang berlapis, yaitu antara Indonesiaialan Eropa. Keberadaan dunia berlapis ini sekaligus menunjukkan masalah yang dialami oleh diri/asing, yaitu masalah inferioritas di hadapan orang Eropa dan keinginan diri/asing untuk tanah air mereka. Kata kunci: literatur perjalanan, penggambaran dunia, pengungkapan diri, representasi liyan (yang lain).
\end{abstract}

\begin{abstract}
In recent years many books have been published containing travel stories, both trips made in Indonesia and abroad. Some are published in the form of short stories, memoirs, travel guide books, even poems or novels. This paper was raised as a form of positive response to the phenomenon. Short stories and letter poems from Praha and to you who awaited Yusri Fajar's snow work become one of the travel stories that
\end{abstract}


tells about the author's journey. By using a changing perspective that is to analyze data and cases, the author uses the theory of travel writing concepts proposed by Carl Thompson in a book entitled Travel Writing (2011). This research describes a person's journey contained in a collection of short stories and poetry anthologies entitled letters from Praha and to you who awaited the snow by Yusri Fajar. Self I foreigners experience geographical dislocations, which result in themselves being in foreign societies and cultures, namely Europe. This study examines Yusri Fajar's short stories and poetry in a travel literature framework as described by Carl Thompson. Thompson explained that there are three ways to see the travel literary pattern, namely by looking at the depiction of the world, self-disclosure, and other representations. The results of his research are that the background of the self/foreign as an alienated person travels by force turns out to influence the travel literary pattern, namely in the depiction of the world, self-disclosure and other representations. From the literary pattern of the journey it can be seen that the self has a layered world, namely between Indonesia and Europe. The existence of this layered world at the same time indicates the problems experienced by the self/foreign, namely the problem of inferiority before the Europeans and the self/foreign desire for their homeland.

Keywords: travel literature, world depiction, disclosureself, liyan representation (the other).

\section{PENDAHULUAN}

Karya sastra sebagai bentuk dari hasil sebuah pekerjaan kreatif pada hakikatnya adalah suatu media yang mendayagunakan manusia. Oleh sebab itu sebuah karya sastra pada umumnya berisi tentang permasalahan yang melingkupi kehidupan manusia. Sastra lahir atas latar belakang dari dorongan dasar manusia untuk mengungkapkan eksistensi dirinya. Masalah manusia dan kemanusiaan serta perhatiannya terhadap dunia realitas berlangsung sepanjang zaman (Sangidu, 2004:2).

Dalam perkembangan tradisi dan pembentukan identitas kesusastraan berbagai faktor memainkan peran dan memberikan pengaruh. Faktor tersebut adalah (1) para sastrawan, (2) karya sastra, (3) masyarakat baik dalam konteks sosio-kultul-ideologis dalam lingkup luas dan tempat berproses kreatif (komunitas sastra), dan (4) para pembaca baik itu para kritikus sastra dan penikmat karya sastra. Berbagai pendahulu tersebut mendorong pencapaian estetik sastrawi, wacana dalam kritik sastra, dan berbagai relasi dialektis sastra dengan dunia yang melingkupinya. (Fajar, 2014:7)

Sebagaimana yang dikekemukakan oleh Thompson, (2011:33) terjadi persentuhan antara masyarakat dan kebudayaan yang pada giliranya akan membentuk sebuah tatanan sosial yangebaru, yang melampaui batasbatas sosial dan kultural setempat. Karya sastra muncul sebagai objek pengetahuan sui generasi yang mempunyai status otologis khusus. Karya sastra bukanlah benda nyata (seperti), mental (psikologis seperti rasa sakit atau penglihatan), atau ideal (seperti segitiga). Sejalan dengan Thompson (Wellek dan Werren, 2016:176) mengemukakan bahwa 
karya sastra adalah sisitem norma dari konsep-konsep ideal yang intersubjektif. Konsep-konsep itu berada dalam ideologi kolektif dan berubah bersama ideologi tersebut. Konsepkonsep itu hanya dapat dicapai melalui pengalaman mental perorangan yang didasarkan pada struktur bunyi kalimat.

Bicara sastra perjalanan tidak bisa mengesampingkan dinamika peradaban, budaya bahkan pelaku perjalanan itu sendiri. Manusia dilahirkan dengan kedua kaki dan dua bola mata sejak lahir yang menjadikannya sebagai makhluk perjalanan. Sejak dulu manusia diharuskan tinggal nomaden dan beradaptasi dengan lingkungan sekitarnya kemudian berevolusi untuk cukup pintar menuliskan kisahnya pada tembok-tembok gua. Secara sederhana, istilah "sastra perjalanan" dapat diartikan sebagai kisah-kisah perjalanan yang dituturkan oleh individu maupun kelompok ketika mereka menghadapi tempat yang baru. Karya-karya sastra perjalanan biasanya berisi gambaran yang cukup detail mengenai pengalaman dan persepsi penulis terhadap sebuah tempat. Sastra seperti ini tidak dimaksudkan untuk memberi informasi-informasi pragmatis tentang sebuah tempat yang dikunjungi melainkan memberikan sebuah deskripsi tentang kebudayaan dan masyarakat lewat pengamatan dan persepsi si penulis.

Berbagai pendapat dan perkembangan genre hingga masa modern ini. (Thompson, 2011:26) mengungkapkan bahwa garis batas yang mengatur definisi 'travel writing' begitu samar. Ia mengungkapkan bahwa genre ini mempunyai potensi untuk menjadi sangat luas dan melahirkan banyak bentuk baru serta berkembang menjadi sub-genre lainnya seperti buku panduan perjalanan, memori, tulisan tentang tempat, deskripsi alam, peta, film perjalanan, dan bahkan banyak hal lainnya.

Secara garis besar, cerita-cerita perjalanan itu mengisahkan orangorang Indonesia dengan berbagai kepentingan melakukan perjalanan keluar negeri. Mereka mengunjungi tempat-tempat yang baru dan asing, mengalami perjumpaan, berinteraksi, dan terlibat dengan orang-orang dari berbagai penjuru dunia. Mereka yang sebelumnya terpisah secara geografis dan historis, bertemu dalam satu momen yang menempatkan mereka pada situasi dan persoalan-persoalan tertentu.

\section{Sastra Perjalanan}

Salah satu di antara definisi yang dapat diberikan pada pengertian perjalanan (travel) yaitu pertemuan antara diri dan liyan, yang disebabkan oleh pergerakan melalui ruang Thompson, (2011:9). Pergerakan ruang ini dibatasi pada pengertian perjalanan yang diuraikan sebagai cerita perjalanan (travel writing). Jika semua perjalanan tentang pergerakan melewati ruang melibatkan diri dan liyan, maka semua cerita perjalanan dewasa ini sebagai produk dari pertemuan antara persamaan dan perbedaan yang dibawa traveler. Dari segi tujuan, cerita perjalanan bertujuan melaporkan dunia yang luas meliputi orang-orang dan tempat-tempat yang asing (unfamiliar) Thompson, (2011:10). Jauh sebelum Thompson 
menyampaikan definisi mengenai cerita perjalanan. Thompson (2011:13) sendiri menggunakan banyak buku referensi yang dilabeli "perjalanan”. Buku-buku tersebut meliputi buku panduan perjalanan, fotografi perjalanan, peta, dan cerita/sastra perjalanan. Fotografi perjalanan menyajikan gambargambar indah suatu lokasi, sedangkan cerita perjalanan menyajikan catatan panjang yang dibuat oleh seorang penjelajah. Cerita perjalanan biasanya dibuka dengan setting bahwa narator keluar dari rumahnya untuk mencapai suatu tujuan, berpetualang, atau mencari pengalaman baru. Selama perjalanannya narator bagaikan musafir yang menjadikan perjalanannya sebagai sebuah pengalaman yang merubah hidupnya sebelum kembali ke rumah dan menyatu dengan lingkungan sosial asalnya.

Pada prinsipnya, sastra perjalanan lebih diarahkan ke dalam bentuk kemodern sastra, artinya sastra perjalanan lebih diarahkan ke bentuk (sub) genre sebagai sastra perjalanan modern. Cerita perjalanan bisa dilihat dengan perspektif yang lebih luas, misalnya etnografi modern, juga bisa dianggap sebagai bentuk sederhana dari sastra perjalanan. Sebenarnya, hal serupa juga terjadi pada teks-teks lain yang menceritakan tentang pengalaman lapangan dan perjalanan (Thompson, 2011:32).

Thompson (2011) mengawali definisi sastra perjalanan dengan menjelaskan apa itu "To travel". To travel adalah perjalanan atau gerakan melalui ruang. Perjalanan melalui ruang ini pada akhirnya menghasilkan negosiasi antara diri dan lainnya. Sastra perjalanan kemudian dipahami sebagai laporan perjalanan tentang dunia yang lebih luas yang dilakukan oleh orang asing di tempat yang asing atau belum diketahui (Thompson, 2011:10). Dengan kata lain definisi tersebut menjadikan negosiasi antara kesamaan dan perbedaan sebagai syarat dalam sastra perjalanan. Definisi ini dirasa masih sangat luas. Artinya, jika melibatkan semua perjalanan (gerakan melalui ruang) yang berisi perjumpaan antara diri dan lainnya, maka semua tulisan perjalanan adalah produk dari pertemuan ini.

Dalam berbagai bentuknya, sastra perjalanan cenderung mempunyai tujuan untuk menyebarkan dan memberitahukan pada masyarakat luas mengenai tempat, budaya, masyarakat yang tidak familiar. Menulis catatan perjalanan adalah menerjemahkan pengalaman perjalanan (travel experience) menjadi tulisan perjalanan (travel text). (Thompson, 2011:21) mengungkapkan bahwa penggambaran yang disajikan penulis, bahkan catatan perjalanan yang menekankan akurasi dan objektivitas, selalu memberikan gambaran parsial yang tidak utuh akan dunia. Meskipun telah berusaha dengan maksimal, ketidakmampuan bahasa (language inadequacy) juga menyebabkan tidak utuhnya penggambaran. Selain itu, pengalaman perjumpaan dengan yang diri/asing kadang menimbulkan wonder, perasaan kagum, takjub, bahkan takut sehingga pengarang terpaku dalam ketakjubannya dan tidak bisa mendefinisikan pengalamannya. Mengingat lapisan-lapisan yang menyebabkan tantangan dan distorsi tersebut, Holland \& Huggan 
(dalam Thompson, 2011:80) berpendapat bahwa travel writing adalah bentuk fiksi dari pengalaman nyata yang dialami oleh penulis (fiction of factual representation).

\section{METODE}

Metode yang digunakan dalam menganalisis puisi adalah metode kualitatif deskriptif. Metode kualitatif merupakan prosedur penelitian yang menghasilkan data deskriptif berupa uraian Metode kualitatif deskriptif artinya yang dianalisis dan hasil analisis berbentuk deskripsi tidak berupa angka-angka atau koefisien tentang hubungan antarvariabel. Dalam penelitian ini data yang dipergunakan berupa kutipan, katakata, frasa, klausa, dan kalimat dalam kumpulan cerpen yang berjudul "Kepada Kamu yang Ditunggu Salju" dan antologi puisi yang berjudul "Kepada Kamu yang Ditunggu Salju”, karya Yusri Fajar. Hal-hal yang perlu dipaparkan dalam penelitian ini meliputi objek penelitian, data, dan sumber data, teknik pengumpulan data, sampling, dan teknik analisis data.

\section{HASIL DAN PEMBAHASAN Penggambaran Dunia Secara Objektivitas}

Penggambaran objektivitas adalah pengambaran yang dihadirkan sesuai dengan apa yang disaksikan dan dialami, tanpa melibatkan perasaan, pandangan, sikap, dan penilaian narator. Dunia yang digambarkan dalam cerita perjalanan dikatakan berjarak dengan penulis (narator). Subbab ini akan memaparkan penggambaran objektivitas yang dilakukan narator pada tempat-tempat yang dikunjungi tokoh atau orangorang yang ditemui di perjalanan. Urutan kunjungan atau penggambaran negara-negara seperti dikemukakan, tetapi juga akan dibahas strategi pengarang untuk memperoleh kepercayaan pembaca. Berikut temuan penggambaran secara objektivitas yang terdapat pada cerpen "Perempuan yang Bercekengkrama dengan Anjingnya".

Seperti yang terlihatkan pada cerpen pembuka yang berjudul "Perempuan yang Bercengkrama dengan Anjingnya”. Sebuah ironi ketersisihan dari dunia kerja produktif yang membuat si ibu tua menerima kos orang asing, yang diberinya hak buat memakai kamar mandi dan dapurnya. Berbagi untuk bisa berkomunikasi agar tidak suntuk dengan anjing yang diperlakukan sebagai makluk cerdas yang bisa didisplinkan, tapi semua tak menghibur karena insting tiap manusia adalah berkomunikasi dan berinteraksi dengan sesama manusia terutama anak-anak.

"Ketika aku tiba di depan tempat tinggalku di Frankfurt untuk pertama kali, aku tidak menyadari ada seseorang perempuan tambun yang melambaikan tangan padaku dari atas balkon. Aku baru tahu ketika sopir taksi yang mengantarku dari bandara memberitahuku. Perempuan tambun itu memberi isyarat agar aku berjalan menuju pintu gerbang apartemen." (Fajar, 2012:1).

Narasi cerita didasarkan pada urutan kejadian atau peristiwa. Narasi di atas merupakan pembuka cerpen berjudul "Perempuan yang Bercengkraman dengan Anjingnya". Narator menggambarkan keadaan 
ketika tokoh Ponco yang baru saja tiba di kota Frankfurt untuk pertama kalinya. Tokoh Ponco mencoba bertemu dengan seorang perempuan yang bernama Irene Laith dia adalah pemilik apartemen. Pintu utama apartemen Irene sudah terbuka, hal tersebut merupakan sebuah tanda bahwa benar perempuan tambun yang melambaikan tangan dari atas balkon tadi merupakan pemilik apartemen yang menyambut tokoh Ponco. Tokoh Irene digambarkan ketika ia mengucapkan kata selamat datang dalam bahasa Jerman kepada Ponco kemudian Irene mempersilakan tokoh Ponco untuk masuk kedalam apartemennya. Sebuah penyambutan secara sederhana yang ditunjukkan tokoh Irene terhadap tokoh Ponco.

Selain penggambaran apartemen, narator juga menggambarkan salah satu sudut ruangan-ruangan apartemen yang begitu kecil. Penggambaran tempat mengawali penggambaran terhadap orang-orang yang ada di sekitar narator lewat tokoh Ponco. Situasi tempat tinggal yang buruk para pedatang ada kaitannya dengan pilihan mereka untuk bermukim terutama di kawasan padat di kota Frankfurt biaya hidup di kota Frankfurt relatif jauh lebih tinggi dibanding kota-kota Jerman lainnya. Penggambaran aktivitas lewat tokoh Ponco secara tidak langsung sebagai penggambaran kondisi Indonesia pada saat itu. Jika dibandingan dengan biaya di negara narator lewat tokoh Ponco, biaya sewa apartemen di Indonesia lebih murah dan lebih menarik bila dibandingkan di Frankfurt. Jika dilihat dari keseluruhan cerita pada kutipan tersebut, maka cerita ini memiliki latar waktu dan tempat. Hal ini terlihat ketika tokoh Irene membagi cerita kepada tokoh Ponco bahwa ia pernah berkunjung untuk berlibur ke Indonesia tepatnya di pulau Bali. Latar waktu terlihat ketika tokoh Irene bercerita mengenai perjalanannya menuju Indonesia ia bercerita tentang keindahan-keindahan pulau Bali ketika ia sedang berlibur saat itu.

\section{Penggambaran Dunia Secara Subjektivitas}

Selain penggambaran dunia secara objektivitas, narator juga menggambarkan dunia secara subjektivitas. Penggambaran dunia secara subjektivitas dalam kumpulan cerpen dan antologi puisi "Surat dari Praha dan Kepada Kamu yang Ditunggu Salju” sendiri terdapat bentuk-bentuk subjektivitasnya. Penggambaran dunia secara subjektivitas melibatkan perasaan dan pikiran narator. Narator menggambarkan dunia dengan disertai perasaan kagum, takut, heran, kecewa, dan senang. Selain itu pada penggambaran secara subjektivitas ini terdapat asumsi, pendapat, penilaian, atau dugaan narator terhadap dunia yang diamati. Berikut ini penggambaran dunia secara subjektivitas sesuai dengan tempat yang dikunjungi narator.

idikan torn Bentuk gambaran subjektivitas pada puisi di bawah ini menggambarkan sebuah keyakinan atau kepercayaan terhadap sesuatu hal dipercayai seseorang.

\section{Hati yang Kembali di Fountai Trevi}

Dengan sekeping uang logam kamu kembali ke Fountai Trevi hatimu bergetar terlempar ke kolam 
berenang mencari kenangan yang pernah tenggelam

semalam mimpimu terkurung
dalam gerbong kereta
meneuju tasiun Roma Termini,
tanpa bayangnya

adakah keyakinan yang hendak kau buktikan?

melihatnya menghampirimu dengan tatapan bersemi dan kata-kata basah seperti hendak tumbuh kembali

(Fajar, 2017:25)

Dalam penggambaran pada puisi di atas terlihat penggambaran terhadap penyair lewat rasa kepercayaan yang di yakini. Terlihat jelas pada puisi di atas mencoba menjelaskan mengenai tradisi atau kepercayaan melempar uang logam ke kolam ke dalam Trevi Fountain. Trevi Fountain sendiri merupakan kolam air mancur yang terletak di Trevi, Roma, Italia yang merupakan salah satu air mancur yang terkenal di dunia. Salah satu kegiatan favorit turis yang datang ke Trevi Fountain adalah melempar koin yang terkait mitos yang berkembang di kolam air mancur ini. Mitos mengatakan kalau seseorang berhasil melempar koin ke kolam Trevi Fountain berarti seseorang itu akan kembali lagi ke kota bersejarah ini. Gambaran subjektivitas inilah yang dibangun penyair lewat puisi ini.

\section{PENUTUP \\ Simpulan}

Cerpen "Surat dari Praha" dan antologi puisi "Kepada Kamu yang Ditunggu Salju" karya Yusri Fajar banyak menampilkan narasi yang menunjukkan bahwa Yusri Fajar adalah seorang penulis travel writing yang banyak menarasikan ceritacerita perjalanannya berdasarkan subjektivitasnya dan informasi secara pribadi terhadap apa yang dialaminya. Pengalaman perjalanan Yusri Fajar ditulis dengan gaya yang menyentuh, banyak menggunakan gaya bahasa yang tergambarkan secara signifikan dengan eksplorasi laporan perjalanan sebagai latar dan plot, sehingga ia dapat dikategorikan juga sebagai penulis travel writing. Dengan penggambaran perjalanan yang memasukkan subjektivitas kedalam tulisannya, Yusri Fajar cenderung memberi gambaran dirinya sendiri secara autobiografi dan lebih kepada kesadaran diri yang ditampilkan dalam setiap perjalanannya.

\section{DAFTAR PUSTAKA}

Fajar, Yusri. 2012. Surat dari Praha. Aditya Media Publising.

2014. Membaca Sastra Jawa Timur. Dewan Kesenian

\section{Illmiah Jawa Timur.}

017. Kepada Kamu yang Ditunggu Salju. Pelangi Sastra.

Sangidu. 2004. Metode Penelitian Sastra, Pendekatan Teori, Metode dan Kiat. Yogyakarta: UGM.

Thompson, Carl. 2011. Travel Writing. New York: Routledge.

Wellek, Rene dan Austin Werren. 2016. Teori Kesustraan. PT Gramedia Pustaka Utama. 